Kohl: a Journal for Body and Gender Research

Vol. 3, No. 1 (Summer 2017)

\title{
Radical Dissent, Feminist Survival: The Dialectics of Migration
}

\author{
Roula Seghaier
}


Multiple local and regional events have informed the publication of this issue. We worked on it during "celebratory" times, when Beirut rejoiced on discourses of Pride, omitting pleas of women, migrants, and refugees, and when institutions commemorated World Refugee Day, stressing the humanitarian aspect of what they called a refugee "crisis." Both events had powerful political and symbolic purposes. They served to reinforce the state's grip on identitarian and national borders while legitimizing institutional discrimination against "others." The naming of the migration the world is witnessing today as a "crisis" justifies the exceptional securitization measures Western host states are taking; overridden with the political spectacular, they emphasize the "unprecedented" nature of such forced migration. The omission of queer migrant voices from Beirut Pride purposefully displaced the focus from state authoritarianism to upper and middle class gay men's "bread and circuses."

This issue was created from the dire need to reinvestigate, deconstruct, and gender migration as a phenomenon that is not modern, although complicated by the neoliberal age. While gender is no alien to migration, it is usually vulgarized through the rights approach, and stripped from all intersectionality by the liberal discourses on social mobility and economic opportunity acquisition for women of color. We wanted to trouble the gender-neutral, liberal, and/or quantitative depiction of the phenomenon. We aimed to expose the state-led media, pop culture, and NGO efforts that are complicit in the demonization of the migrants, essentialization of their cultures, and fetishization of their bodies. We aspired to debunk the ways in which these efforts reinforce national and imagined boundaries, and feelings of nationalism and homonationalism on the side of Western countries on the one hand, and amplify the tales on the backwardness of people of color on the other. We wanted to challenge these discourses and to participate in the feminist archiving of the collective memory of migration.

We had all the above in mind when working on this issue, though we had not yet imagined the ways its theme would spill over the journal's futurity. Kohl is now an independent platform, one that took part in a different type of migration and sought the shores of queer feminist autonomy. Migration comes in different shapes, some more fragile than others, due to the vulnerabilities exposed and stakes put on the line. It will always find critics shouting that the grass is not always greener on the other side, and others questioning the loyalty to the homeland or to the patriarch. What does migration threaten, and where do we find explanations to the multitude of political and moral panics surrounding bodies trespassing and/or testing the porosity of borders? These are some of the questions we attempted to answer in this volume.

The issue opens with "Kohl: an Independent Feminist Political Project," an announcement by Ghiwa Sayegh, our editor in chief. Inspired by Sara Ahmad's latest work, the piece is a manifesto on the ethos of our journal and its political vision. It discloses the ways in which we chose to Live a Feminist Life. Sayegh credits the efforts of the hundreds of feminists who make our survival possible. She outlines our undocumented histories, our understanding of solidarity, and our politics to plot together, not to save each other. 
This issue is illustrated by Hala H. Hassan, whose work is featured in our section on Artivism. Currently residing in New York, Hassan navigates the challenges of being a subject of migration. Believing in the power of design activism, she illustrates "The Human Trap" that characterizes the lives of aliens, like herself.

In Openings, Amira, Gholama, Mawn, Sama, and Zakaria, feminist activists based in Lebanon, discuss their experiences in relation to the historical and theoretical breaks in the feminist and LGBT movements in Lebanon. "Institutional Migrations and Radical Survival: Beyond Organizational Splits" is a conversation among some of those whose voices have been absented, opinions ridiculed, and positionalities questioned due to their "absence" from an imaginary "ground." Decisions to abstain from participation in efforts that normalize the police state or identitarian politics were dismissed as treachery and never as radical survival. The conversation tries to mend this discursive gap in the ways we understand institutional migration, collective work, and solidarity.

Collective labor was absent from Beirut Pride Inc., which Lara Bitar deconstructs in her opinion piece, titled "Against Assimilationist Projects: Towards Queering Our Political Imaginations." The uncollaborative work surrounding Beirut Pride, registered as a trademark, purposefully obliterated the past and rewrote histories, failing to see the multitudes of ways it is complicit with the capitalist system. It turned people and their struggles into commodities, serving the idea that markets provide solutions for social ills. This apolitical representation of BP manufactured citizen-subjects focusing on representation and appearance. By doing so, it safeguarded the event from religious and state institutions, but paradoxically made the population it was set to celebrate more vulnerable by sidelining those at the bottom of the homonationalist food chain: the immigrants.

Next, "A Liberated Life? Thoughts on the Paradoxical Binds of Queer Refuge," Hana Masri eloquently argues that oblivion, subjugation, and oppression do not only affect those who migrated, but also those who remained in their countries of citizenship. With the current demographic changes, the imagined backwardness of refugees helps simultaneously uphold racist nationalistic borders, as well as the narratives celebrating and mythologizing Western states as queer havens. Paradoxically, the narrative of the queer refugee embraced by these states bolsters the same inaccurate stories that justify their exclusion and the reinforcement of borders. She overviews the mainstream Canadian celebratory media portrayal of Syrian queer refugees, and problematizes its underlying racism, unmasking its paradoxical nature. The irony does not escape anyone: such narrative reinforces tales of Arab and Muslim heterosexist societies burdened with parochial sexual systems, all while putting every racialized body as suspect.

The second essay, "Reflections on Intersections: Searching for an Anti-Racist, Pro-Migrant Feminist Response to Sexual Assault Committed by Migrants," takes the matter further. Amira Elwakil discusses the appropriation of far-right rhetoric of the racialization of brown bodies and the state discourses on their backwardness. The notion of "rapeugees" is coined to "prove" a connection between Muslim/Brown migrants and sexual harassment, thereby perpetrating imaginative geographies of "civilization" versus "savagery." Elwakil critiques xenophobic and Islamophobic narratives that match sexual harassment and rape to particular ethnicities or geographical location, while calling for a feminist response to such assaults committed 
by migrants. She makes clear that a feminist denouncement of these assaults and the holding of pro-migrant politics are not mutually exclusive. Rather, it is possible, albeit difficult, to address sexual violence and xenophobia simultaneously, through a transversalist approach, and feminists shall make this their task.

Our research section opens with Marlene Soulier's "Racializing Homophobia: Tracing Sexual Political Discourse within Europe's 'Refugee Crisis' in Berlin." Soulier discusses how the German state reinvents itself as tolerant in opposition to refugee bodies as a site of backwardness, coated with stereotypes of inherent inability to embrace queerness and difference. She argues that German organizational practice and rhetoric molds a sexual identity contingent with citizenship, one that refugees are bound to assimilate into, all the while orientalizing homophobia. These discourses solidify the interpretive authority of producing knowledge on gender and sexuality as the exclusive right of white voices, and thereby sustain racist fabrications.

"(Dis)-Intersecting Intersectionality in the Time of Queer Syrian-Refugee-ness in Lebanon" is an effort to complicate feminist theoretical approaches to questions of migration. Sabiha Allouche uses intersectionality and assemblage theory to transcend the stale and fixed figure of a Syrian refugee that is informed by intersectionality. She argues that intersectionality alone fails to understand the complexity of refugee identity and praxis, as it is secondary to agency because it involves conscientious navigation, and that agency is, and shall remain, "knowledge that is yet to be." She studies the ecosystem within which these identities operate in a Lebanese context, and advises us to "think ambiguously as methodology," since by doing so, scholarship can avoid the trap of speaking on behalf of others and the pitfalls of operating within binaries.

In "Bodies of Hope and Disruption," Jillian Grisel writes about the "medicalization of [the] misery" of migrant domestic workers in Lebanon who are incarcerated. Disclosing her positionality in terms of privilege and vulnerabilities, she discusses the time she spent teaching touch therapy and English to women prisoners. She employs indigenous, Black and Transnational feminist intuitive, emotional, and spiritual ways of knowing to illustrate the racial hierarchies, complicated by mental health and the prison industrial complex, that keep capitalism in place. This piece reclaims acts of care and the power of touch, often portrayed as trivial or individualistic, as acts of resistance. This is a tribute to the collective imagination of the "unsaid," and to the dialectic nature assigned to skin, able to oppress, organize, and heal us.

Still in the theme of hope, Yara Mamdouh Ahmed studies how queer bodies imagine their existence, movement, and relations to governments and to borders in the neoliberal age. Struck by an observation she made during an LGBTQ+ workshop in Egypt, "On Dream Making and Aspired Migration of Queer Bodies" challenges the imposed staticism of essential identities enforced by the state in its dichotomies between the legal/illegal, citizen/immigrant, and public/private as part of state formations of the "other." She discusses the damage caused by the rights approach that ground every aspect of being and becoming in the notion of the state, thus participating in the fortification of the oppressive institution. 
Perhaps the most flagrant example of the strengthening of oppressive institutions through a liberal and onedimensional rights approach lies in the pinkwashing politics of the Israeli occupier. In the last research article of this issue, "Queering the Occupation: Settler Colonial Sexualities in the Era of Homonationalism," Ralph Haddad deconstructs Israel's self-proclaimed positions as a liberal sanctuary for the queer, feeding on Islamic and homophobic portrayals of Palestinians, thereby delegitimizing their struggle. In this regard, Haddad links between the reconfiguration of gayness as whiteness in South Africa, and the reliance on state apparatuses to enforce the cooptation of the gay international, a mechanism similar to the imaginative labor of creating Zionism in terms of sexuality. He eloquently explains the detrimental role homonationalization plays as parcel of the military industrial complex, quoting Palestinian activist, Sami Shamali, that "There is no magic pink door in the Apartheid Wall."

In her satirical testimony, "Thank God I am White," Muntaha Abed speaks of other separation walls, of the borders of language, color, and citizenship that she experienced as a Palestinian student in London. Although said borders are commonly assigned a metaphorical nature, they bare increasing weight in times of demographic change. These attributes "other" migrants and/or tokenize them. Abed hence critiques the ways in which intersectionality in "the fantasy world of the whites" is stripped of its political nature, and how it becomes a liberal project of merging all oppressions into one.

We close the issue with Golchehr Hamidi-Manesh who reviews Sara Ahmad's Living a Feminist Life. She discusses the invisible brick walls that fashion bodies as foreign and claim them as artificial, denying them authenticity or locality. Bodies and instincts know things that we were socialized into and forced to forget. We are trained to turn a blind eye to daily contradictions and cognitive dissonances, at times for survival and at times for a pursuit of happiness. And when we resist, our bodies are branded as ungrateful. To live a feminist life is to embrace the daily struggle of problematizing everything at whatever cost it takes.

As we publish this issue, an activist, a Migrant Domestic Worker, a mother, and a friend of many, is forced to leave Lebanon and almost a quarter of a century of collective struggle behind. She leaves with no pension, no healthcare, and no recognition like many others before her. The state forces many bodies into a space of precariousness ensured by rigid borders of labor and residency rights. It forces them into a place of social waste that is "out of sight," behind bars, and outside borders. Migration in all its forms is not only a claim to a right or a praxis of a freedom, it is an act of radical dissent and survival. 